\title{
Mediações e letramento midiático: uma aproximação necessária
}

\section{Mediations and media literacy: a necessary approach}

\author{
Matheus Cestari Cunha \\ Marli dos Santos ${ }^{2}$
}

Resumo: Neste texto procuramos lançar um olhar sobre a Educação Midiática inspirado na Teoria das Mediações, na perspectiva de Jesús Martín-Barbero (1987, 1997, 2018), considerando a comunicação como aspecto essencial para se pensar a Educação Midiática. Trata-se de estudo que propõe a viabilidade de aproximações entre as duas propostas teóricas, partindo do conceito de letramento midiático e das competências midiáticas apresentadas por Celot e Pérez-Tornero (2009), tendo em vista que as mediações são um aspecto essencial para compreendê-las, e que extrapolam os fatores de entorno.

Palavras-chave: Teoria das Mediações; Letramento midiático; Comunicação

\begin{abstract}
In this text we seek to take a look at the European media literacy concept, taking into consideration the Theory of Mediations, from the perspective of Jesús Martín-Barbero (1987, 1997, 2018), considering communication as an essential aspect to think about media literacy. This is a study that includes a theoretical reflection that proposes the feasibility of approximations between the two theoretical proposals, starting from the European concept of media literacy and the media skills presented by Celot and Pérez-Tornero (2009), considering that mediations are an essential aspect to understand them, that extrapolate the environmental factors.
\end{abstract}

Keywords: Theory of Mediations; Media Literacy; Communication

1 Faculdade Cásper Líbero. São Paulo, SP, Brasil.

http://orcid.org/0000-0002-9936-7624 E-mail: matheuscestaricunha@gmail.com

2 Faculdade Cásper Líbero. São Paulo, SP, Brasil.

http://orcid.org/0000-0003-0953-2663 E-mail: msantos@casperlibero.edu.br 


\section{Introdução}

Neste artigo abordamos a Teoria das Mediações e o letramento midiático, numa tentativa de propor, ao final, aproximações entre as duas perspectivas teóricas. Partimos dos mapas das mediações de Martín-Barbero (1987, 1997, 2018), que são propostas teórico-metodológicas que evoluíram desde a sua primeira proposição, e do letramento midiático, com foco nas competências midiáticas, conforme Celot e Pérez-Tornero (2009).

O primeiro mapa foi proposto em 1987, na obra seminal de Martín-Barbero, De los medios a las mediaciones: comunicación, cultura y hegemonia, posteriormente atualizada em 1997 e 2018. Tentamos abarcar essa evolução, com foco no mapa mais recente, o qual insere a tecnicidade como mediação básica. Também apresentamos as críticas feitas ao autor sobre o conceito de Mediações, o que dificulta o desenvolvimento de uma teoria latino-americana de Comunicação.

No campo da Educação Midiática, o caminho foi apresentar o conceito de letramento midiático, como vertente preocupada com as competências midiáticas, adotada por pesquisadores europeus e norte-americanos. Dentre outras abordagens nesse campo, encontramos a educomunicação, perspectiva latino-americana; literacia para os media, em Portugal; por fim, Alfabetização Midiática e Informacional, expressão cunhada pela Organização das Nações Unidas para a Educação, a Ciência e a Cultura (UNESCO), na tentativa de unificar a área.

Apesar de relevante, não vamos aprofundar a discussão sobre as vertentes da Educação Midiática. Cada um desses conceitos tem uma finesse, uma abordagem, uma especialidade dentro do campo, que se aplica às demandas de cada pesquisa. Propomos, assim, partirmos de um pensamento comunicacional comum, e, nesse sentido, a América Latina tem uma contribuição fundamental: a Teoria das Mediações.

A perspectiva latino-americana da Comunicação busca compreender o sujeito a partir do seu cotidiano, da sua relação com o contexto que o circunda, da negociação de sentido feita a partir das mediações. Essa abordagem é mais abrangente do que a do letramento midiático, 
quando aborda os fatores de entorno, que dizem respeito ao acesso e disponibilidade dos meios e aparatos, às políticas públicas de mídia-educação, à indústria midiática e à sociedade civil. Por isso, refletimos sobre as possíveis pontes teóricas e metodológicas entre o Sul e o Norte, na tentativa de ampliar o conceito de letramento midiático, levando em consideração a Teoria das Mediações como um marco teórico na interface Comunicação/Educação.

\section{As mediações no Pensamento Comunicacional Latino- americano}

Assim como os demais campos das ciências humanas e sociais aplicadas, o dos estudos da Comunicação abarcaram várias tendências teóricas e metodológicas, originárias do continente europeu e dos Estados Unidos, especialmente, a partir da Mass Comunication Research, que no seu conjunto abarcou a perspectiva Funcionalista; a Teoria Crítica, a partir da Escola de Frankfurt, com inspiração marxista; o Estruturalismo, que ganhou destaque com os intelectuais franceses; e os Estudos Culturais, vindos da Escola de Birminghan, entre outras correntes teóricas. Na América Latina, as Teorias da Comunicação começaram a se desenvolver somente a partir dos anos 1950, porém, ainda não tinham uma emergência local e eram influenciadas pelas correntes já mencionadas.

Lopes (2003) fornece uma interpretação de como essas teorias apareceram na América Latina. Para a autora, a corrente funcionalista tem dominância nos estudos de comunicação até dos dias atuais, com mais destaque dos anos de 1950 a 1980. Em 1950, se desenvolvem pesquisas baseadas em métodos quantitativos, como medições de audiência e sondagens de atitudes e motivações. Na década seguinte, o Centro Internacional de Estudos Superiores de Comunicação para América Latina (CIESPAL) realiza pesquisas descritivas e de estudos de comunidade ao criar a linha de Pesquisa Comunicação e Desenvolvimento. Em 1970, o CIESPAL continua com essa tradição de pesquisa, concentrando-se em políticas de comunicação nacionais e internacionais. $\mathrm{O}$ aspecto 
descritivo dá lugar a uma análise sistêmica da produção e circulação da comunicação nos anos 1980. A extensa tradição funcionalista não deu conta das especificidades latino-americanas:

O uso do paradigma funcionalista nos estudos de Cultura e Comunicação de Massa em sociedades subdesenvolvidas vai transpor para estas tão somente o conceito de estratificação social, pelo qual os estudos de cultura dos estratos mais baixos não apresentam especificidade alguma, além de modalidades "atrasadas" de relações e representações sociais (LOPES, 2003, p. 53).

É necessário enfatizar que nos anos 1970 a influência da teoria crítica foi importante na América Latina, devido ao contexto de repressão durante as ditaduras militares em diversos países, apontando a manipulação da indústria cultural e sua lógica de mercado. Outro aspecto é a concepção elitista de cultura, a ideia de que a "alta cultura" seria capaz de transformar a sociedade e desenvolver formas de consciência crítica a qual coloca grande parte das pessoas como vítima desse processo, sem qualquer resistência (LOPES, 2003).

Porém, no final dos anos 1970 e começo dos anos 1980, após a superação do cenário de repressão através da redemocratização dos países latino-americanos, particularmente do Brasil, as Teorias da Comunicação passaram a ser influenciadas pelos Estudos Culturais. As novas tecnologias da comunicação, a transnacionalização, a cultura e a comunicação popular começam a aparecer como objetos de estudos (LOPES, 2003).

Nesse contexto, percebe-se a necessidade de uma Teoria da Comunicação própria, que leve em consideração as contradições históricas latino-americanas e as mestiçagens culturais.

As contribuições latino-americanas e brasileiras nesse sentido articulam-se objetivando a construção de uma Teoria da Recepção, cuja originalidade para a Teoria da Comunicação tende a ser reconhecida internacionalmente. As poucas, porém influentes, pesquisas empíricas sobre leitura crítica dos meios, recepção de telenovela, lazer e cotidianidade, usos populares dos meios, culturas urbanas e outras, apontam para essa construção 
teórica desmontando as teses de passividade e de manipulação dos receptores pelos MCM. Consideramos que nessa teorização estão envolvidos esforços para retomar a unidade do objeto da Comunicação, evitando o parcelamento e o reducionismo na análise de seus componentes, tendência que constitui uma das características mais negativas no atual estado da pesquisa em comunicação (LOPES, 2003, p. 69-70).

Corroborando a análise de Lopes, Barros Filho e Martino (2003) apontam que o receptor tardou a ser incorporado nos estudos da comunicação, que se concentrou primeiramente nos efeitos dos meios de comunicação de massa, depois na produção e nas características dos meios.

Portanto, a Teoria das Mediações é uma construção que faz uma inversão nessa lógica de manipulação dos receptores pelos meios de comunicação e o acentua no processo comunicacional. Martín-Barbero (1987) propõe que o indivíduo negocie os sentidos dos conteúdos midiáticos com o contexto que o circunda a partir das mediações. A proposta do autor, diferentemente da Teoria de Usos e Gratificações, apresentada por Blumler (WOLF, 1995), cujo foco são as motivações dos indivíduos para consumirem determinados conteúdos midiáticos, coloca as mediações como centrais, as quais atravessam os sentidos produzidos pelos receptores.

Apesar das mediações serem a premissa da proposta teórica do autor, ele se recusa a formular uma definição para o termo, pois as medicações são um processo contínuo e passam por transformações constantes. Com o avanço nos estudos dessa teoria e observando os mapas propostos desde o livro seminal de Martín-Barbero, podemos encontrar alguns elementos para uma livre interpretação, ou uma pista, que nos conduz a contemplar as mediações como um processo no qual aspectos que fazem parte do contexto que circunda o indivíduo se relacionam com ele, direta ou indiretamente, em diferentes intensidades. São considerados o sujeito, seu contexto e as relações estabelecidas.

Alguns autores apontam deficiências na apresentação de um conceito de mediações por Martín-Barbero. Signates (2006, p. 69) afirma que a 
definição feita pelo autor é nebulosa, e que enquanto "os limites teóricos e metodológicos não ficarem suficientemente definidos, dificilmente o uso da noção de mediação dotará os estudos de comunicação de um suporte teórico que possa ser admitido como uma superação das teorias e interpretações existentes".

Signates fez um mapeamento da obra seminal de Martín-Barbero, identificando que o conceito de mediação aparece 37 vezes: "Dessas citações, em 21 oportunidades o autor a utiliza como categoria vinculante de dicotomias específicas e, em maioria, antinômicas. Nas demais, efetua simples citações, sem um comprometimento explícito com sua definição" (2006, p. 6-7). Para sustentar ainda mais a sua argumentação, Signates (2006) apresenta cinco formas em que o conceito de mediação pode ser definido, de acordo com a obra de Martín-Barbero, para confirmar a falta de precisão epistemológica:

como constructo ou categoria teórica; como discursividade específica; como estruturas, formas e práticas vinculatórias; como dispositivo de viabilização e legitimação da hegemonia ou resolução imaginária da luta de classes no âmbito da cultura; e ainda como instituição ou local geográfico (SIGNATES, 2006, p. 62).

Sodré (2002, p. 250) concorda com o posicionamento de Signates ao afirmar que "o conceito de mediação não consegue ultrapassar a sua enorme imprecisão cognitiva, já apontada por vários autores, inclusive o próprio Raymond Williams, uma de suas fontes originárias”. Eles são acompanhados por Maio (2018, p. 8-9) que, ao analisar as confluências entre as propostas de Martín-Barbero e Orozco, concluiu que "um dos gargalos de sua proposta se encontra, entretanto, na definição nebulosa de mediação", mas minimiza a crítica mencionando exagero de Signates ao negar a existência da teoria: "Martín-Barbero, inegavelmente, é vago na definição de mediação, mas tamanha radicalização pouco contribui para a construção teórica, até porque os estudiosos da obra barberiana avançaram sobremaneira no desenvolvimento conceitual”.

Outro crítico da Teoria das Mediações é Ciro Marcondes Filho (2008). Ele afirma categoricamente que não se trata de uma Teoria da 
Comunicação, afirmando ser, na maioria das vezes, "uma sociologia, uma antropologia, uma economia política das comunicações (quase sempre: de massa), tudo isso muito afastado do estudo da própria comunicação interpessoal, por irradiação ou virtual”. O autor ainda ressalta que a

Teoria da Comunicação latino-americana é uma ilha solitária, que busca com seus próprios - e muitas vezes escassos - recursos teóricos dar conta da complexidade de um processo comunicacional em tempos de mudanças vertiginosas, superação de paradigmas e aceleração tecnológica. Talvez por isso encontre poucos ecos nos Estados Unidos e na Europa (MARCONDES FILHO, 2008, p. 69).

Entretanto, Martín-Barbero (1987, 1997, 2018) sistematiza essas premissas através de mapas teórico-metodológicos. É importante ressaltar que devido ao caráter contextual e relacional, não é fácil identificar essas mediações. A representação das mediações - que ainda é bem complexa - visa à operacionalização da referida teoria a partir da leitura da sociedade atual, e de como o indivíduo se apresenta nela e das negociações de sentido que faz com que o contexto o circunda. Não é possível afirmar que todas as mediações estejam contidas ali, mesmo porque essa seria uma abordagem instrumental do mapa. Consideramos essa amplitude necessária, dada a natureza interdisciplinar da teoria, talvez essa seja a sua maior força e virtude.

A utilização do mapa fornece várias respostas, porque abarca os fenômenos relacionados ao contexto do indivíduo. Entretanto, ele pode ser extrapolado e permite várias entradas a partir do que se pesquisa. Para exemplificar, tomamos a proposição mais recente do autor. 
Figura 1 - Mutações Comunicativas e Culturais

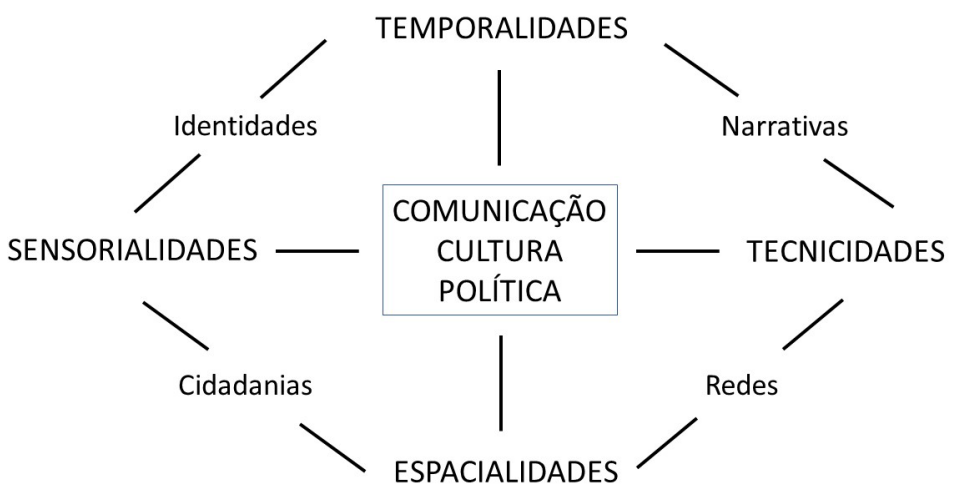

Fonte: LOPES (2018, p. 58)

No centro do mapa, vemos a comunicação, cultura e política como mediações fundantes. É importante destacar a emergência de uma razão comunicacional, que reconfigura a ordem social de uma maneira paradoxal. Por um lado, os indivíduos estão conectados a uma rede que permite trocas globais, favorecendo lógicas agenciadoras do mercado e uma aparente coesão social. De outro, se assiste à valorização da individualidade e uma volta às raízes mais primitivas da humanidade, através de discursos e práticas que lembram mais o instinto que a racionalidade (MARTÍN-BARBERO, 2018, p. 13).

Considerando a cultura, de acordo com Martín-Barbero (2018), a fronteira teórica entre antropologia e sociologia - na qual para a primeira cultura é tudo e, para a segunda, se resume em fenômenos sociais do cânone das artes e das letras - se encontra borrada. Afinal, hoje existem mecanismos nos quais a produção cultural, de bens simbólicos, é oferecida de acordo com os seus públicos consumidores. Então,

a cultura escapa a toda compartimentalização, irrigando a vida social por inteiro. Hoje são sujeito/objeto de cultura tanto a arte quanto a saúde, o trabalho ou a violência, e há também cultura política, do narcotráfico, 
cultura organizacional, urbana, juvenil, de gênero, cultura científica, audiovisual, tecnológica etc. (MARTÍN-BARBERO, 2018, p. 14).

Ao levar essa reflexão para a política o autor percebe a necessidade de "reconfiguração das mediações em que se constituem os novos modos de interpelação dos sujeitos e de representação dos vínculos que coesionam a sociedade" (MARTÍN-BARBERO, 2018, p. 14). Os meios de comunicação ganharam uma grande importância ao constituir os discursos e a própria ação política. Eles participam da vida pública e engendram seus pontos de vista na sociedade a partir da força de suas mediações. A televisão, principalmente, possibilita esse processo por meio do "eixo do olhar", enquadrando certas representações a partir da mais conveniente. Dessa maneira, então, a política deve recuperar seu nexo simbólico, sua capacidade de agregação em um cenário de constantes tensões com a cultura e mercado.

Martín-Barbero apresenta, também, quatro mediações básicas: temporalidades, espacialidades (desde sua primeira proposição), sensorialidades e tecnicidades. Antes, a temporalidade social era baseada na programação da TV, que orientava o cotidiano do sujeito - o horário da novela, do jogo de futebol, por exemplo. As espacialidades, neste caso, eram mais estáticas e mais fáceis de serem compreendidas. O convívio familiar em torno da televisão acabava sendo a "situação primordial de reconhecimento” (MARTÍN-BARBERO, 1987, p. 293).

Porém, as temporalidades não são mais as mesmas. Martín-Barbero (2018) destaca a rapidez dessas transformações e a dificuldade de ancoragem, decorrentes do ritmo ditado pelo capitalismo. Sendo assim, o presente difuso faz o sujeito buscar sua identificação no passado. Há uma febre pela memória, um certo apego às âncoras do passado.

Essas disposições da temporalidade acabam por configurar certas espacialidades, expressas na proposição mais recente da teoria. Dessa forma, Martín-Barbero (2018) vai categorizar quatro espaços: o habitado, pela necessidade humana de um lugar para manifestar sua individualidade e ter acolhimento; o imaginado, onde ocorrem as trocas imateriais e simbólicas e o sujeito projeta e constitui suas relações com o contexto 
e com o outro; o espaço produzido, a partir das demarcações territoriais e a produção material, fruto de conquistas e acordos, de invenções, como as máquinas, que diminuíram distâncias e nos distraem; o último, é o espaço praticado pela cidade moderna que amplifica o anterior, porque amplia a perspectiva objetiva do lugar e das coisas para as relações subjetivas, como o anônimo no urbano e suas interações em busca da própria identidade, considerando-se aqui o entrelaçamento entre o espaço virtual e o material. A presença da submediação das redes - que aparece pela primeira vez nesse mapa - confirma a intenção do autor em dar destaque a essa mediação.

As sensorialidades são um adensamento de outras mediações que aparecem nos mapas anteriores, conferindo importância às relações comunicacionais próximas, cotidianas. Segundo John, Ribeiro e Silva (2019, p. 124, tradução nossa), o desafio é "pensar a sensorialidade como uma mediação central na compreensão do entendimento não só das relações que os sujeitos estabelecem com as narrativas midiáticas, mas também, com a maneira deles se relacionarem com o mundo onde vivem". Fazem parte dessa ideia, ainda, a cognitividade, que deriva da competência cultural, da capacidade de recorrer a conhecimentos prévios e/ou scripts para compreender determinado fenômeno comunicacional e a ritualidade, que confere o nexo simbólico à comunicação.

A relação dessas mediações com a tecnicidade se dá através da evolução histórica. No primeiro mapa (1987), a tecnicidade aparecia ainda como um conjunto de ideias bem abstratas, embutidas dentro das competências culturais e ainda nem tinham essa nomenclatura. A partir do segundo mapa (1997) essa mediação aparece como uma submediação, com a emergência da internet no fim do século XX. Depois, a tecnicidade é fruto de mais preocupações de Martín-Barbero (2010), que reforçava a necessidade de se encarar as novas espacialidades e temporalidades em um cenário social relacionado às tecnologias digitais. Nesse sentido, o adensamento da mediação da tecnicidade apresentado no último mapa (2018), alçando-a ao estágio de mediação básica, é coerente com a evolução do pensamento do autor. 
Em entrevista à Mariluce Moura (2009, p. 3), Martín-Barbero menciona a evolução da sociedade, desde o entorno natural, ao urbano e agora ao tecnocomunicativo, que supera a ideia de aparelho ou meio, e no qual o sujeito deve estar preparado para lidar. Daí a necessidade de desenvolvimento das diversas sensorialidades.

Outra submediação, cidadanias, ganha relevância no atual mapa com o adensamento da tecnicidade (potencial de participação) e que abrange as relações entre instituições e indivíduos, direitos e deveres dos cidadãos. Antes era apontada como submediação da institucionalidade, tensionada com a socialidade. Essas relações, por sua vez, também são importantes agentes na construção da identidade dos sujeitos, única submediação que permanece em relação aos mapas anteriores, especialmente em um cenário de constante e veloz transformação.

Na sequência, apresentamos alguns conceitos essenciais para a compreensão do letramento midiático, enquanto vertente da Educação Midiática, um campo interdisciplinar entre Educação e Comunicação.

\section{Letramento midiático: competências e contexto}

O conceito de letramento, dentro do campo da Educação Midiática, é definido como: "a capacidade de aceder aos media, de compreender e avaliar de modo crítico os diferentes aspetos dos media e dos seus conteúdos e de criar comunicações em diversos contextos", sendo que o objetivo "é aumentar o conhecimento das pessoas acerca das muitas formas de mensagens dos media que encontram no seu dia a dia" (UNIÃO EUROPEIA, 2009, p. 227). As mensagens midiáticas podem ser de vários gêneros, formatos e linguagens: programas, vídeos, filmes, imagens, textos, sons que chegam até os indivíduos por diferentes formas de comunicação.

O letramento midiático expõe uma série de competências que o sujeito deve adquirir (ÁREA, 2008; PÉREZ \& DELGADO, 2012; FERRÉS, 2007), mas adotamos o referencial de Celot e Pérez-Tornero (2009), que sistematizam o processo dividindo as competências em individuais (uso, compreensão crítica, participação e comunicação) e fatores de entorno, 
propondo uma pirâmide na qual há uma ordenação na aquisição de competências.

De acordo com os autores, as competências de uso estão mais ligadas ao próprio funcionamento dos aparelhos eletrônicos. Entretanto, devem ser desenvolvidas de maneira holística a fim de o sujeito atender a todas as suas necessidades, que vão desde o entendimento de simples funções às funções mais complexas: capacidade de diferenciação de aparelhos e suas funcionalidades e de transmitir esses conhecimentos a outros de maneira formal. Deve também ter "consciência crítica sobre questões técnicas dos aparelhos” (2009, p. 37 - tradução nossa).

As competências de compreensão crítica abrangem o conhecimento sobre o ecossistema midiático. O primeiro fator é o entendimento sobre o conteúdo midiático e suas funções, com as seguintes competências vinculadas:

- Codificar e decodificar, com o objetivo de entender o título e o conteúdo do que foi veiculado; - Competência para avaliar, comparar e contrastar criticamente os conteúdos midiáticos, conferindo valor a informação com base nas necessidades do usuário; - Explorar e procurar por informação de maneira ativa; - Capacidade de sintetizar e resumir uma informação a partir de diferentes publicações; - Capacidade de misturar e reciclar os conteúdos midiáticos [isso acontece quando alguém compartilha uma coisa e faz um "textão" no Facebook, por exemplo] (CELOT; PÉREZ-TORNERO, 2009, p. 39 - tradução nossa).

O segundo fator, conforme Celot e Pérez-Tornero (2009, p. 40), é o conhecimento sobre a mídia e sua regulação, que abrange as competências de avaliação crítica referente a regulamentações, diversidade e “direitos da produção midiática”, além de buscar conhecimento sobre a mídia para avaliar e interpretar os conteúdos midiáticos.

O terceiro fator reside no comportamento do próprio usuário, que se aproveita das capacidades semióticas e linguísticas dos indivíduos no processo de interpretação dos conteúdos midiáticos, "é a maneira de cada indivíduo compreender e se relacionar com o mundo ao redor dele" (CELOT; PÉREZ-TORNERO, 2009, p. 40 - tradução nossa). 
As competências comunicacionais e participativas também são divididas em três fatores: relações sociais, participação cidadã e criação de conteúdo. No aspecto das relações sociais, Celot e Pérez-Tornero (2009, p. 42) advogam que os sujeitos devem ter as competências de "iniciar e manter contato" pelas mídias e redes sociais; compartilhar comportamentos e se apropriar de outros, sendo que a "mídia reforça essa capacidade mimética, especialmente nos adolescentes e jovens".

Mesma coisa acontece com as competências de participação cidadã, que exigem habilidades de participação e compartilhamento conscientes; de gerenciamento e colaboração para "atingir determinados objetivos"; de apresentar uma "identidade específica” relacionada ao objetivo de cada relação estabelecida; de interagir com "múltiplas instituições de maneira apropriada, utilizando os canais adequados" (CELOT; PÉREZ-TORNERO, 2009, p. 43 - tradução nossa).

A produção de conteúdo, de acordo com os autores (2009, p. 44), desde enviar um e-mail, comentar um post no Facebook, ou algo mais complexo como a produção de notícias é reforçada pelas mídias e redes sociais. Sendo assim, são necessárias as competências de compartilhar ferramentas, estimular trabalho cooperativo, produzir conteúdos originais, ter habilidade para desenvolver "condições, normas ou fatores que afetem a criação de conteúdo feita pela própria mídia, seja por pressões, regulações, leis, direitos, estéticas etc.”.

Por fim, os fatores de entorno são expostos a partir de cinco esferas, que contém alguns indicadores. A primeira é o acesso e disponibilidade dos meios e aparatos, levando em consideração a quantidade de smartphones a cada 100 habitantes, o acesso a internet, a circulação de jornais e a quantidade de televisores e telas de cinema. A segunda trata da mídia educação em virtude da presença do letramento midiático no currículo das escolas, no treinamento de professores, nas atividades educacionais e os recursos financeiros disponíveis para a realização desses processos. A terceira se manifesta na adoção de políticas públicas relacionadas a promoção de agentes e atividades reguladoras ligadas ao letramento midiático. A quarta e quinta estão relacionadas com as iniciativas da 
própria indústria midiática em promover esse processo, principalmente em ações conjuntas com organizações da sociedade civil (CELOT e PÉREZ-TORNERO, 2009).

A proposição de Celot e Pérez-Tornero (2009) foi revisada posteriormente por dois órgãos parceiros da Comissão Europeia: o Danish Tecnology Institute (DTI) e a European Association for Viewers Interests (EAVI) que produziram um novo relatório (2011). A classificação de competências permanece, entretanto, com caráter piramidal. O relatório concluiu que a aquisição delas acontece de maneira holística, não há como hierarquizá-las. Além disso, acrescentaram alguns fatores de entorno individuais, como idade, gênero, educação e renda. Entretanto, questionam a forma como os fatores de entorno são aplicados no bojo das competências, porque

nem a disponibilidade dos meios, nem as regulações, nem as políticas públicas e da indústria parecem ser entendidas como aspectos do letramento midiático per se, mas como circunstâncias propícias para o avanço do letramento midiático em uma escala social (201 l, p. 22 - tradução nossa).

Sendo assim, a grande questão está em como essas competências se articulam entre si e são adquiridas pelos indivíduos e como esses fatores de entorno são trabalhados pelo conceito de letramento midiático. O próprio conceito de competências é amplamente discutido na Europa. Infelizmente, não há espaço para abordarmos em profundidade todos os aspectos, mas é importante levantar o que dois autores pensam a respeito.

Marín (2012) realiza uma retrospectiva histórica, relatando que a ideia de competência ganhou força nos anos 1970, sempre ligada a questões laborais. Posteriormente, foi evoluindo para outros aspectos da natureza humana, porém, sempre de maneira instrumental, descritiva e limitante. O autor conclui seu raciocínio deixando uma dúvida no ar. Ele diz não saber se

as competências são produto da articulação total dos conhecimentos, das habilidades, das destrezas e das atitudes/valores de um indivíduo, ou se a 
combinação de alguns destes pode gerar a erupção de uma competência, ou se, por acaso, é possível que cada um destes por si só provoque um desenvolvimento das competências em algum campo da prática social e/ou profissional, ou, também, se existe uma relação gradual entre estes âmbitos e, como consequência, se as competências geradas em algum produz a constituição de qualquer outro (MARIN, 2012, p. 4).

Drexel já é mais afirmativo: "O conceito inclui não só os conhecimentos formais e informais e capacidades, mas também os 'valores pessoais', as 'motivações e comportamento”' (2003, p. 7). Além dele, Ferrés (2007), e Ferrés e Piscitelli (2012) afirmam que competências, neste aspecto do letramento midiático, "são definidas como uma combinação de conhecimentos, aptidões e atitudes adequadas ao contexto". Mas, de que contexto estão falando?

Aqui se encontra um possível limite do letramento midiático. O contexto é relacionado aos aspectos institucionais, como políticas públicas, disponibilidade de meios e currículo escolar (CELOT \& PEREZ-TORNERO, 2009). Mesmo quando acrescidos por fatores como renda, gênero, idade e educação, a compreensão desse entorno complexo fica limitada. Além disso, o questionamento levantado pelo relatório do DTI e EAVI (2011) de que os fatores de entorno parecem ser compreendidos apenas como um condutor para o avanço e amplificação do letramento midiático na sociedade sustenta essa limitação. Ao considerá-los dessa forma, excluem a influência direta do contexto na aquisição de competências individuais, algo que pode ser observado.

Apesar de situar-se na interface Comunicação/Educação, os paradigmas comunicacionais europeu e norte-americano são pragmáticos e elitistas (LOPES, 2003), o que pode limitá-los diante de um cenário comunicacional tão complexo como o atual. A seguir, apresentamos as possíveis pontes entre a Teoria das Mediações e o letramento midiático, na tentativa de explorar a importância do contexto que circunda o indivíduo - para além dos fatores de entorno - no processo de aquisição de competências midiáticas. 


\section{Considerações sobre pontes entre Sul e Norte}

Como já dissemos na introdução deste artigo, compreendemos que cada conceito do campo da Educação Midiática tem sua finesse, sua própria especialidade. Trabalhamos com o letramento midiático, porque ele dá conta, diretamente, de refletir sobre o ecossistema comunicacional, das relações entre as pessoas e os meios de comunicação, do cinema à internet.

Entretanto, uma das chaves está na interpretação de como essas relações acontecem, suscitando uma breve reflexão epistemológica do fenômeno, para pontuar como a Teoria das Mediações pode criar pontes entre o pensamento latino-americano e o resto do mundo.

Apesar das críticas já mencionadas anteriormente, a Teoria das Mediações evoluiu nas últimas duas décadas. Em que pese a clareza de um conceito que estabeleça os limites teóricos e metodológicos das "mediações”, conforme alguns autores apontam, sua perspectiva atual encontra correspondência com a descrição de um ecossistema comunicacional, com a presença de novos atores, como técnicos especialistas na operacionalização de algoritmos e negociantes que trabalham com pesquisa de mercado para adequar os produtos midiáticos às necessidades dos consumidores (LEWIS \& WESTLUND, 2015).

Martín-Barbero (2018) aponta que, para compreender esses processos, são necessárias tecnicidades específicas que são adquiridas por meio das diversas sensorialidades e com a presença de outras submediações, como as redes, a cidadania e as narrativas, por exemplo.

Nesse sentido, consideramos que conceito de letramento midiático necessita de um paradigma comunicacional que não trate apenas da relação do sujeito e seu entorno - na perspectiva europeia -, porque o ecossistema comunicacional é muito mais complexo. A negociação de sentido que o indivíduo realiza com o contexto que o circunda a partir das mediações é um aspecto importante para compreender como esse processo ocorre. Sendo assim, um paradigma comunicacional que limite o objeto de estudo parece não dar conta de abarcar as complexidades 
produzidas a partir desse pensamento. São necessárias pontes entre Sul e Norte para um diálogo na perspectiva ampla advinda das mediações.

$\mathrm{Na}$ prática, isso significa que se deve promover mudanças na forma de pensar, analisar e estudar como os sujeitos adquirem, aprimoram e manifestam as competências midiáticas. Há uma primeira abordagem nesse caminho, considerando as mediações como uma variável desse processo. Como exemplo, uma pesquisa com jovens universitários do $\mathrm{ABC}$ Paulista, na tentativa de mapear quais as competências existentes nos jovens e como as mediações atuam no processo de aquisição destas dá alguns sinais importantes (CUNHA, 2020).

Os instrumentos de pesquisa (questionários e entrevistas) foram baseados no conjunto de competências de Celot e Pérez-Tornero (2009), apresentado no tópico anterior. É importante ressaltar que nenhum dos sujeitos da pesquisa participou de alguma iniciativa formal de Educação Midiática. A conclusão é de que mesmo alguns participantes não possuindo "competências relacionadas à compreensão crítica, apresentavam competências de participação”, produzindo conteúdo. Diz o autor: "Acreditamos que isso se dá porque as mediações são uma variável importante na aquisição de competências midiáticas e devem ser levadas em consideração ao se analisar esse processo" (CUNHA, p. 100).

Todos os entrevistados citaram alguma mediação: família, amigos, escola, professores, identidade. Esses aspectos fazem parte das sensorialidades dos indivíduos e são alguns exemplos de como o contexto que circunda se relaciona com a compreensão dos conteúdos midiáticos, a partir das negociações estabelecidas.

Portanto, da mesma forma que o autor, acreditamos que existe uma via de mão dupla entre o letramento midiático e a Teoria das Mediações. O processo de aquisição de competências - e sua utilização prática pelo indivíduo - tem as mediações como aspecto essencial, assim como também fazem parte das sensorialidades, na medida em que o letramento midiático é uma ferramenta importante para a compreensão que o sujeito tem do mundo atual. 
Ao apresentar a evolução dos mapas teórico-metodológicos de Martín-Barbero como proposta para os estudos da comunicação, tendo em vista as dinâmicas das mediações na negociação de sentido em processos comunicacionais, com foco na contemporaneidade, pudemos observar possíveis pontes. Em vez dos fatores de entorno, as mediações poderiam fornecer novas pistas para entendermos e contribuirmos para os estudos em letramento midiático, especificamente quando tratamos das competências adquiridas em contextos informais.

\section{Referências}

AREA, M. La innovación pedagógica con tic y el desarrollo de las competencias informacionales y digitales. Investigación en la escuela, n. 64, p. 5-17, 2008.

BARROS FILHO, C. de; MARTINO, L. M. S. O habitus na comunicação. São Paulo: Paulus, 2003.

CELOT, P.; PÉREZ-TORNERO, J. M. Study on Assessment Criteria for Media Literacy Levels. A comprehensive view of the concept of media literacy and an Understanding of how media literacy level in Europe Should Be Assessed. Brussels: European Commission. 2009. Disponível em: https://ec.europa.eu/assets/eac/culture/library/studies/ literacy-criteria-report_en.pdf. Acesso em: 10 jun. 2020

CUNHA, M. C. Jornalismo participativo, letramento midiático e mediações: a manifestação de competências midiáticas em jovens universitários do ABC paulista. $101 \mathrm{lf}$. Dissertação (Mestrado em Comunicação Social) - Faculdade Cásper Líbero - São Paulo.

DREXEL, I. Two Lectures: The Concept of Competence - an Instrument of Social and Political \& Change Centrally Coordinated Decentralization - No Problem? Lessons from the Italian Case, Working Paper. 2003. Disponível em: http://www.ub.uib.no/elpub/ rokkan/N/N26-03.pdf. Acesso em 5 de jun de 2020.

DANISH TECNOLOGIAL INSTITUTE; EUROPEAN ASSOCIATION FOR VIEWERS' INTERESTS. Testing and Refining Criteria to Assess Media Literacy Levels in Europe - Final Report. Brussels: European Commission. 2011. 243p.

FERRÉS, J. La competencia en comunicación audiovisual: propuesta articulada de dimensiones e indicadores. Quaderns del CAC, n. 25, p. 9-17, 2007.

FERRÉS, J.; PISCITELLI, A. La competência mediática: propuesta articulada de dimensiones e indicadores. Comunicar, v. 19, n. 38, p. 75-82, 2012.

JOHN, V. M.; RIBEIRO, R.; SILVA, G. H. SENSORIALIDAD: la mediación que siempre estuvo presente. In: Nilda Jacks; Daniela Schmitz; Laura Wottrich (Org.). Un nuevo mapa para investigar la mutación cultural: Diálogo con la propuesta de Jesús Martín-Barbero. 1ed.Quito: Ciespal, 2019, v. 1, p. 117-136. 
LEWIS, S. C.; WESTLUND, O. Actors, Actants, Audiences, and Activities in Cross-Media News Work. Digital Journalism, n. 3, p. 19-37, 2014.

LOPES, M. I. V. A teoria barberiana da comunicação. Revista Matrizes, v. 12, n. 1, p. 39-63, 2018.

MAIO, A. M. D. Teoria das mediações sociais: refinamento ou obsolescência? In: Revista da Associação Nacional dos Programas de Pós-Graduação em Comunicação. Brasília: E-compós, v. 19, n. 3, set./dez. 2016.

MARCONDES FILHO, C. Martín-Barbero, Canclini e Orozco. Os impasses de uma teoria da comunicação latino-americana. Porto Alegre: Famecos, v. 1, n. 35, p. 69-85, abril 2008.

MARÍN, F. G. El concepto de competencias, Revista Ibero-americana de Educação, v. 4, n. 60, p. 1-13, 2012.

MARTÍN BARBERO, J. De los medios a las mediaciones: Comunicación, Cultura y Hegemonía. Barcelona - México: Gustavo Gili, 1987.

MARTÍN-BARBERO, J. Dos meios às mediações: Comunicação, Cultura e Hegemonia. 5aed. Rio de Janeiro: UFRJ, 1997.

MARTÍN-BARBERO, J. Dos meios às mediações: 3 introduções. Revista Matrizes, v. 12, n. 1, p. 9-31, 2018.

MOURA, M. As formas mestiças da mídia. Entrevistador: Mariluce Moura. São Paulo: Pesquisa Fapesp, n. 163, p. 10-15, set. 2009. Disponível em: https://revistapesquisa.fapesp.br/2009/09/01/as-formas-mesticas-da-midia/. Acesso em: 27 jul. 2019.

PEREIRA, F. H.; ADGHIRNI, Z. L. O jornalismo em tempo de mudanças. Disponível em: http://repositorio.unb.br/bitstream/10482/12443/1/ARTIGO_JornalismoTempoMudancas.pdf. Acesso em: 7 fev. 2019.

SIGNATES, L. Estudo sobre o conceito de mediação e sua validade como categoria de análise para os estudos de comunicação. In: SOUSA, Mauro Wilton de (Org.). Recepção mediática e espaço público: novos olhares. São Paulo: Paulinas, 2006, p. 55-79.

SODRÉ, M. Antropológica do espelho. Petrópolis, RJ: Vozes, 2002.

UNIÃO EUROPEIA. Jornal Oficial da União Europeia. Recomendação da Comissão sobre literacia mediática no ambiente digital para uma indústria audiovisual e de conteúdos mais competitiva e uma sociedade do conhecimento inclusiva. Recomendação 2009/625/ CE de 20 de agosto de 2009.

WOLF, Mauro. Teorias da comunicação. 4. ed. Lisboa: Editorial Presença, 1995. 247p. 


\section{Sobre os autores}

Matheus Cestari Cunha - Doutorando em Ciências da Comunicação na Universidade do Minho, em Portugal. Graduado em Comunicação Social - Jornalismo pela Universidade Metodista de São Paulo (2017) e Mestre pela Faculdade Cásper Líbero (2020). Escolhi começar o mestrado logo após a conclusão da graduação, porque tenho grande interesse na carreira acadêmica. Quero ser professor e pesquisador. Na dissertação, realizei uma aproximação teórica entre jornalismo participativo, letramento midiático e Teoria das Mediações, bem como uma pesquisa empírica sobre esses processos com jovens universitários do ABC Paulista. Também possuo experiência prática com letramento midiático, ao integrar a equipe do projeto Dante em Foco (2015). No presente artigo, realizou a estruturação do artigo em tópicos e apresentou os principais conceitos.

Marli dos Santos - Doutora em Ciências da Comunicação pela Escola de Comunicações e Artes da Universidade de São Paulo (2004) e mestre em Comunicação Social pela Universidade Metodista de São Paulo (1998). Graduada em Comunicação Social, habilitação em Publicidade e Propaganda (1979) e Jornalismo (1989) pela UMESP. Estágio pós-doutoral pela Universidade Federal de Goiás (UFG) com a supervisão da profa. Dra. Ana Carolina Rocha Pessoa Temer. É docente permanente do Programa de Pós-Graduação em Comunicação da Faculdade Cásper Líbero, linha de pesquisa Jornalismo, Imagem e Entretenimento. Líder do Grupo de Pesquisa Jornalismo contemporâneo: práticas para emancipação social na cultura tecnológica. Coordenadora do GT Estudios sobre periodismo da Associación Latinoamerica de Investigadores de Comunicación (ALAIC) e Coordenadora do GT Gêneros Jornalísticos, da INTERCOM - Sociedade Brasileira de Estudos Interdisciplinares da Comunicação. Atuou como coordenadora e docente do Programa de Pós-Graduação em Comunicação Social da UMESP, de 2011 a 2017. Foi docente titular do curso de Jornalismo da UMESP, de 1999 a 2017, tendo assumido a coordenação de 2011-2013. Orientou inúmeros projetos e trabalhos de conclusão de curso e projetos de iniciação científica. Atuou como docente no Programa de Comunicação Jornalística da PUC-SP e no Sindicato dos Jornalistas Profissionais no Estado de São Paulo. Foi repórter, editora, assessora de imprensa e gerente de comunicação em grandes empresas. No presente artigo, complementou o conteúdo e realizou a revisão final do texto.

Data de submissão: 11/09/2020

Data de aceite: 25/02/2021 